\title{
Dimensão Política do Serviço Social na Assistência Estudantil: Limites e Possibilidades
}

\author{
Erica Giles Bragança'
}

Angela Maria Caulyt Santos da Silva²

\section{Resumo}

Este artigo objetiva analisar a dimensão política do Serviço Social na Política de Assistência Estudantil do Instituto Federal de Educação, Ciência e Tecnologia do Espírito Santo. Resulta de uma pesquisa empírica, de abordagem qualitativa, realizada com assistentes sociais desse Instituto. Desenvolve a coleta de dados por meio de entrevista e os analisa mediante a técnica de análise de conteúdo. Conclui que, por meio da dimensão política do Serviço Social, os assistentes sociais do Ifes contribuem com a construção emancipatória dos estudantes, a partir do desenvolvimento da direção social e de processos de organização e de mobilização social.

Palavras-chave

Serviço Social; Dimensão política; Assistência estudantil.

Political Dimension of Social Work in Student Assistance: limits and possibilities

\begin{abstract}
This article aims at analyzing the political dimension of Social Work in the Student Assistance Policy of the Federal Institute of Education, Science and Technology of Espírito Santo (Instituto Federal do Espírito Santos - IFES). It is the result of an empirical research, with a qualitative approach, carried out with social workers from that Institute. It develops data collection through interviews and analyzes them using the content analysis technique. We concluded that, through the political dimension of Social Work, IFES' social workers contribute to the emancipatory construction of students, based on social direction development, organization processes and social mobilization.
\end{abstract}

\section{Keywords}

Social Work; Political dimension; Student assistance.

Artigo recebido em fevereiro 2020

Artigo aprovado em maio de 2020 


\section{Introdução}

Iniciamos o debate afırmando nossa compreensão de que o exercício profissional do assistente social, enquanto expressão material e concreta de seu processo de trabalho, "[...] explicita a dimensão política da profissão e o reconhecimento da condição de sujeitos de direitos daqueles com os quais atua" (MARTINELLI, 2011, p. 498). Diante disso, almejamos discutir sobre o Serviço Social na Política de Assistência Estudantil (PAE), por meio de uma construção de saberes que possam resultar em intervenções que consolidem o direito à educação.

Portanto, este artigo ao analisar a dimensão política do Serviço Social na PAE do Instituto Federal de Educação, Ciência e Tecnologia do Espírito Santo (Ifes) apresenta como objetivos específicos: compreender a direção social do Serviço Social no Ifes e conhecer o processo de organização e mobilização do Serviço Social nessa instituição.

A coleta de dados foi realizada por meio de entrevista semiestruturada com seis assistentes sociais com acúmulo de experiência na PAE. No intuito de resguardar a identidade dos referidos participantes, foram utilizados pseudônimos do alfabeto grego: Alfa, Beta, Gama, Delta, Sigma e Ômega. No que se refere aos dados, foi utilizada a técnica de análise de conteúdo como "um conjunto de técnicas [...] visando obter [...] indicadores [...] que permitam a inferência de conhecimentos relativos às condições de produção/recepção destas mensagens" (BARDIN, apud MINAYO, 2013, p. 303).

Ao desenvolvermos um estudo acerca da dimensão política do Serviço Social não significa que estamos dissociando o Serviço Social de suas dimensões principais de maneira fragmentada, mas sim buscando elementos para sua melhor compreensão.

O debate da dimensão política do Serviço Social nos faz considerar sua articulação com duas grandes dimensões:

[...] a) de um lado, as condições macrossocietárias que tecem o terreno sócio-histórico em que se exerce a profissão, seus limites e possibilidades que vão além da vontade do sujeito individual; 
b) de outro lado, as respostas de caráter ético-político e técnico-operativo apoiadas em fundamentos teórico-metodológicos (IAMAMOTO, 2004, p. 11-12).

Nesse sentido, buscaremos o entendimento da concepção política da questão social, tendo em vista que essa

[...] permeia a sociabilidade da sociedade de classes e seus antagonismos constituintes. Envolve disputa social, política e cultural em confronto com as desigualdades socialmente produzidas (YAZBEK, 2014, p. 683).

Portanto, discutir a dimensão política do Serviço Social na Política de Educação torna-se necessário, pois, conforme Witiuk (2004), na mediação entre Estado e sociedade civil, a escola constitui-se um espaço de muita relevância para atuação do assistente social, por ser um aparelho de hegemonia fundamental no processo de organização de uma nova cultura, a partir de uma base ético-política pautada em valores e princípios crítico-humanistas.

\section{Interlocuções no espaço educacional e diálogos com a assistência estudantil}

A inserção do assistente social na política de educação não é recente, contudo, não existia muito acúmulo de produção de conhecimento nessa área. Atualmente, segundo Silva (2012), ocorre o adensamento do debate e das experiências acerca dessa política, que proporciona a construção de espaços de discussões e articulações em diversos Estados e municípios brasileiros.

Consoante a esse processo, segundo o Conselho Federal de Serviço Social (CFESS), é importante compreender a complexidade das instituições educacionais e dos processos políticos que as particularizam, tendo em vista que as requisições postas a esse profissional estão afınadas com tendências contraditórias (CONSELHO FEDERAL DE SERVIÇO SOCIAL, 2011). 
Dessa forma, compreendemos que o desenvolvimento da dimensão política do Serviço Social na Política de Educação contribui para que os usuários construam e ou fortaleçam sua consciência crítica, mas, além disso, possibilita o planejamento de estratégias de organização e de mobilização social para a construção de uma nova cultura, tendo em vista que a escola é o

[...] espaço privilegiado de produção e socialização do saber e deve se organizar por meio de ações educativas que busquem a formação de sujeitos éticos, participativos, críticos e criativos (PIANA, 2009, p. 76).

Contudo, a realidade da maioria das escolas brasileiras é de não existência de assistente social em seus quadros profıssionais, ainda que a categoria profissional tenha se organizado e se mobilizado, articulada ao conjunto CFESS/Conselho Regional de Serviço Social (CRESS), a fim de aprovação do Projeto de Lei $n^{\circ}$ 3.688/2000, que dispunha sobre a prestação de serviços de Psicologia e de Serviço Social nas escolas públicas de educação básica. Após muita luta e resistência, quase 20 anos depois, finalmente o referido Projeto de Lei foi efetivado pela Lei $\mathrm{n}^{\circ}$ 13.935, de 11 de dezembro de 2019 (BRASIL, 2019).

Ao contrário da maioria das escolas brasileiras, os assistentes sociais, historicamente, fazem parte das equipes profissionais dos IFs e, de acordo com o CFESS (2011, p. 25), “[...] a ampliação e a interiorização da rede de Institutos de Educação, Ciência e Tecnologia e as demandas por programas e ações de assistência estudantil" se apresentam como fenômenos que incidem sobre as requisições postas aos assistentes sociais na política de educação.

A assistência estudantil no Brasil teve início com ações de caridade e de filantropia e, mesmo quando passou a ser prevista em suas Constituições, ficou reduzida ao repasse material. Assim, ela se confunde com a história da assistência social que, segundo lamamoto e Carvalho (2014), utilizava o Serviço Social dos casos individuais a fim de readaptar o indivíduo e proporcionar-lhe o mínimo indispensável (IAMAMOTO; CARVALHO, 2014). 
A partir de pressões realizadas pelos sujeitos do Movimento Estudantil foi aprovado, em julho de 2010, o Decreto $n^{\circ} 7.234 / 2010$, que trata do Programa Nacional de Assistência Estudantil (PNAES), com a finalidade oferecer condições de permanência dos jovens na educação superior pública federal, abrangendo os Institutos Federais de Educação, Ciência e Tecnologia (IFs) (BRASIL, 2010). É importante, contudo, destacar seu caráter seletista, pois, conforme o art. 5, serão atendidos de maneira prioritária aqueles:

[...] estudantes oriundos da rede pública de educação básica ou com renda familiar per capita de até um salário mínimo e meio, sem prejuízo de demais requisitos fixados pelas instituições federais de ensino superior (BRASIL, 2010).

Nesse contexto, a PAE do Ifes foi construída com participação dos estudantes, das equipes técnicas e de seus dirigentes máximos e apresenta-se em Programas de Apoio à Formação Discente, constituídos em dois grupos: Programas Universais, cujo atendimento será oferecido preferencialmente a toda comunidade discente, e Programas Específicos, que visam o atendimento ao aluno em vulnerabilidade social (INSTITUTO FEDERAL DE EDUCAÇÃO, CIÊNCIA E TECNOLOGIA DO ESPÍRITO SANTO, 2011a).

Os Programas Universais têm o objetivo de favorecer o desenvolvimento integral dos estudantes e são acessíveis a toda comunidade escolar. Já os Programas Específicos são desenvolvidos por meio dos Programas de Atenção Primária - que considerarão, prioritariamente, a situação socioeconômica dos estudantes, que será avaliada pelo profissional de Serviço Social - e dos Programas de Atenção Secundária (refere-se ao Programa Auxílio-Monitoria), que contribuem para formação acadêmica, mas não são determinantes para a permanência dos estudantes (INSTITUTO FEDERAL DE EDUCAÇÃO, CIÊNCIA E TECNOLOGIA DO ESPÍRITO SANTO, 2011a).

Ademais, a PAE prevê que suas ações sejam desenvolvidas por diversos profissionais, dentre eles o assistente social, que busca anali- 
sar as expressões da questão social em sua totalidade e problematizá-las, em articulação com os demais atores da escola na promoção de debates que protagonizem e valorizem um ensino voltado para a emancipação, ainda que a consciência política não seja suficiente para o processo de emancipação, a luta não seja necessariamente realizada por todos os assistentes sociais, tampouco exclusiva desses profissionais, mas sim por toda a classe trabalhadora.

\section{Resultados e análises que revelam o fazer profissional}

Apresentamos os resultados baseados na análise dos limites e das possibilidades acerca da dimensão política do Serviço Social na assistência estudantil do Ifes, pois “[...] é nesse campo atravessado por feixes de tensões que se trabalha e nele [...] são abertas inúmeras possibilidades ao exercício profissional" (IAMAMOTO, 2015, p. 79).

Dessa forma, propomo-nos a estudar os limites e as possibilidades da dimensão política do Serviço Social na assistência estudantil do Ifes por sermos trabalhadores dessa instituição e concordarmos com Mota (2014) que assevera que, ao preservar as abordagens dos limites e possibilidades da atuação profissional e fortalecer a relação entre os espaços profissional e acadêmico, é possível que os problemas cotidianos sejam superados, a partir da pesquisa e da investigação propiciada por essa articulação.

\section{Dimensão Política do Serviço Social}

É a partir da realidade concreta que propomos discutir a dimensão política do Serviço Social no Ifes, conforme apontamentos das assistentes sociais entrevistadas:

A gente vem de uma profissão que se inicia dentro de um contexto político e isso vem sendo moldado de acordo com que esse cenário vai mudando (CAMA).

Todo contexto que envolve a nossa atuação é permeado pela política (ALFA).

A gente tem que estar sempre contextualizando a demanda além do que está acontecendo (BETA). 
É uma profissão que tem no seu Código de Ética a defesa de uma sociedade melhor, com igualdade social e com garantias de direitos (ÔMECA).

Se dá no momento em que a gente tem uma concepção de Estado e de sociedade. Então a política é a relação entre pessoas que têm consciência da vida em sociedade. Então a gente atua muito nesse recorte. Tanto trazendo essa perspectiva dessa consciência, dessa vida mais autônoma, menos alienada, e essa concepção da relação com o Estado, sendo uma relação de direitos (SIGMA).

Nesse sentido, Yazbek (1999, p. 19) destaca que

[...] sociedade civil e Estado resultam de relações sociais contraditórias e produzem instituições e políticas voltadas ao atendimento das necessidades sociais e políticas da sociedade.

É nesse campo que se inserem os assistentes sociais que se utilizam também de sua dimensão política para o enfrentamento das expressões da questão social, com a classe trabalhadora.

No entanto, vivemos em uma fase de despolitização da questão social, em que os fatores estruturais da pobreza são desconsiderados, demandando que a classe trabalhadora se reinvente, assim como recrie seu protagonismo político (YAZBEK, 2014).

Para o desenvolvimento da dimensão política do Serviço Social na PAE, Delta destaca que essa dimensão perpassa:

Pela garantia de direitos. O que antes era considerado um favor do diretor com recursos de custeio, hoje é um direito, tem uma rubrica própria e eles têm direito a esse acesso. Então esclarecer esse ponto a eles, que não é dado, foi conquistado e, a partir disso, tentar trabalhar a dimensão de escolha, de autonomia, de protagonismo, de responsabilidade deles dentro dos programas.

Assim, o desenvolvimento da dimensão política do Serviço Social compreende a formação política dos estudantes. Nesse contexto, as assistentes sociais entrevistadas compartilharam experiências que expressam possibilidades: 
Iniciamos um trabalho com um grupo livre. Os alunos iam para conversar, se eles quisessem, na hora que quisessem. Emergiam muitas questões no debate político - não político micro-partidário, mas político mesmo. Se debatia o que estava acontecendo no mundo. Os meninos traziam os mais diversos temas. Então eu acho que, na amplitude de intervenção, esse foi o trabalho mais rico na concepção da formação política. Eu me colocava numa posição mais de escuta do que de palestra, porque o projeto é potencializar a voz deles (ÔMECA).

Temos um projeto sobre sexualidade e drogas, fazendo grupos de discussão, não só de palestra, mas de ouvir os alunos. Eu acho que só esse momento já é uma forma da gente trabalhar a autonomia (BETA).

Além disso, a formação política e, portanto, a dimensão política, extrapola os espaços coletivos e se apresenta como possibilidade, inclusive nos atendimentos individuais, tornando-se transversal a toda ação profissional:

As ações com grupos e atendimento individual têm um cunho completamente político. Eu tenho alunos que vêm simplesmente conversar questões de gênero, questões das relações dentro da escola. Na percepção deles, é uma questão individual, mas é totalmente interligado nas relações sociais [...]. Eu acho que a dimensão política, o trabalho político é orgânico da profissão, então eu penso que até quando a gente está fazendo uma entrevista para o auxilio assistencial financeiro, a gente pode fazer intervenções que tenham um cunho político, da forma como a gente conduz a entrevista. Ali você já faz uma ação política, porque você potencializa o sujeito, inclusive, para poder se colocar enquanto sujeito de direitos (ÔMECA).

No entanto, Gama reconhece que é necessário ampliar o espaço de formação política, inclusive para o debate sobre educação:

a gente utiliza isso muito pouco até para estar repensando algumas outras coisas dentro da educação. Esses alunos são supercriativos, têm grande potencial para estar trazendo outras questões. 
Por sua vez, são apontados alguns limites responsáveis pela pouca utilização da PAE como instrumento de formação política:

A falta de espaço limita muito, porque a gente não tem um auditório. Quando a gente faz as reuniões com os alunos, tem aluno que fica em pé. Causa certo desânimo também da nossa parte. Os nossos gestores têm dificuldade de entender essa instituição. Se eles já têm dificuldade pra ver as atividades do cotidiano, que dirá uma discussão que ultrapassa a sala de aula (GAMA).

Esses limites de falta de espaço físico e a falta de entendimento por parte da gestão, sobre a concepção ampliada de educação, reduzem a compreensão e a efetivação do trabalho do assistente social. No entanto, é muito importante que se busque o diálogo entre os atores envolvidos na educação, mesmo que essa não constitua numa incumbência muito simples, segundo destaque:

eu acho que o desafio é articular também com os demais setores da escola, setores de ensino, professores. Fazer esse trabatho em rede dentro da própria escola (SIGMA).

Em virtude dos dados apresentados, o desenvolvimento da dimensão política do Serviço Social não é tarefa fácil, pois essa dimensão é

[...] um dos principais desafios da formação e do exercício profissional, na medida em que se articula com a direção sociopolítica e com as estratégias mobilizadoras na realização das suas práticas (MOTA, 2014, p. 695, grifo nosso).

\section{Direção Social do Serviço Social}

De acordo com Santos (2012), para que o Projeto Ético Político (PEP) não se degenere em uma mera carta de intenção, a formação e o exercício profissional exigem uma direção política crítica. No entanto, é possível que exista, no conjunto de assistentes sociais de uma mesma instituição, tanto profissionais com uma perspectiva conservadora, quanto profissionais com uma perspectiva crítica, que utilizem o processo educativo para ampliação de direitos e 
almejem o horizonte da emancipação humana, pois os assistentes sociais, conforme lamamoto (2015, p. 79, grifo da autora),

[...] exercem a função de um educador político; um educador comprometido com uma política democrática ou um educador envolvido com a política dos 'donos do poder'.

Em vista dos argumentos, observamos que a direção social do Serviço Social se apresenta numa perspectiva emancipatória de acordo com os princípios preconizados pelo projeto profissional, como defensores de uma política de educação pública, universal e de qualidade e isso se constitui como uma possibilidade:

Eu acho que essa percepção do mundo, do nosso contexto, do aluno, de quem é esse sujeito, a nossa formação dá uma base para compreensão do aluno como protagonista (GAMA).

A escola é um locus que reproduz um padrão de sociedade conservadora. É uma estrutura que quer ser preservada e a gente visualiza a necessidade de mudança, de debater, porque estamos em construção (SIGMA).

Isso porque, conforme apontamento do CFESS (2012, p. 20), nós, assistentes sociais, inspirados

[...] na direção social do nosso projeto ético-político [...] sinalizamos para a imprescindibilidade de disseminar uma cultura crítica da liberdade, da democracia e dos direitos humanos, diferenciando-os da abordagem liberal-burguesa.

Outra possibilidade para a atuação profissional é vislumbrada quando Ômega demonstra concordância com a perspectiva do PEP acerca da concepção dos direitos sociais:

a gente tem um protagonismo muito grande em considerar esse sujeito como sujeito de direitos, uma vez que a sociedade o tempo todo tenta subalternizar o pobre e a gente consegue ultrapassar essa dimensão (ÔMEGA). 
Nesse sentido, torna-se relevante a análise de que

[...] colocar os direitos sociais como foco do trabalho profissional é defendê-lo tanto em sua normatividade legal, quanto traduzi- los praticamente, viabilizando a sua efetivação social (IAMAMOTO, 2015, p. 78).

\section{Organização e mobilização social dos assistentes sociais}

A organização e a mobilização social são expressões das práticas educativas, formuladas e implementadas pelas classes sociais na luta pela hegemonia. Portanto, não são exclusivas do Serviço Social, mas são elementos constitutivos do corpo teórico prático dessa profissão (ABREU; CARDOSO, 2009).

Para o entendimento da organização e da mobilização social dos assistentes sociais na PAE, compreendemos ser importante situar o leitor acerca dos órgãos consultivos de discussão dessa política: o Fórum Interdisciplinar de Assistência Estudantil (Fiae), que tem como principal objetivo propor diretrizes e políticas para a assistência estudantil; e a Comissão Gestora da Política de Assistência Estudantil (CGPAE), de natureza consultiva, que tem "[...] a responsabilidade de propor a forma de gestão dos recursos orçamentários destinados à assistência estudantil, no âmbito de cada campus" (INSTITUTO FEDERAL DE EDUCAÇÃO, CIÊNCIA E TECNOLOGIA DO ESPÍRITO SANTO, 2011a, p.15).

Assim, iniciaremos as análises acerca da organização e da mobilização social dos assistentes sociais no processo de construção da PAE que, em nossa concepção, não se encerra na elaboração de seu documento-base, por considerarmos as experiências que decorrem de seu processo de elaboração e de implantação, sobretudo por se tratar de uma política jovem, tendo em vista que nossa análise está pautada no concreto, a partir do contato com a realidade.

Observamos que a participação no Fiae se constitui em uma possibilidade, pois é um espaço que dá visibilidade ao processo de organização e mobilização social das assistentes sociais entrevistadas: 
eu observo que a organização e mobilização dos assistentes sociais ocorrem através do Fiae. Eu acho que os assistentes sociais se mobilizam bem nessa construção da política de assistência estudantil (ALFA).

No que diz respeito à CGPAE, os dados apontam que o panorama das discussões fica reduzido no âmbito do recurso financeiro: na definição de valores dos auxílios, na utilização do recurso da assistência estudantil em alguma ação ou programa e na aprovação de edital da assistência estudantil.

Os resultados apontam o limite de que a CGPAE nos campi está formalizada, mas não está atuando de maneira efetiva. Sua atuação é muito restrita ao espaço formal de reuniões, ainda que elas não sejam tão frequentes, mas, quando ocorrem, as atividades ficam a cargo da equipe de assistência estudantil:

A CCPAE existe, mas não tem tido reunião. Alguns representantes não participavam. Isso foi desanimando a gente e, no final das contas, não valia à pena fazer reunião para ter presença de pessoas que não queriam se envolver. Chegava no final da reunião da CCPAE e só estava a gente (CAMA).

A maioria dos participantes considera que os assistentes sociais do Ifes possuem organização e mobilização social no que diz respeito à sua atuação profissional nessa política e isso se constitui uma possibilidade:

Os assistentes sociais se mobilizam bem nessa construção da política de assistência estudantil. Todos eles são muito interessados, muito focados nesse trabalho (ALFA).

Eu achei a participação dos colegas do Serviço Social muito ativa, muito forte. Hoje eu acho um pouco mais enfraquecida. Acho que são momentos. O grupo aumentou um pouco mais, é um desafio. Eu acho que a participação do Serviço Social foi boa, inclusive para trazer essa concepção de direito (SICMA).

Eu acho que, dentro das nossas possibilidades, é uma categoria que se organiza bem, apesar de que a gente tem muita demanda (CAMA). 
Se for olhar o pouco que eu conheço de outras instituições, a gente é bem mobilizado e organizado, porém essa demanda de trabalho sobrecarrega a gente, que não consegue pensar coisas além, ou pensar rápido, com qualidade (DELTA).

Na dimensão técnica, é uma relação organizada e uma mobilização bem eficiente, enquanto categoria. Mas não acho que tem mobilização no sentido mais amplo da palavra (ÔMECA).

Nesse sentido, as participantes apontam que a grande demanda de trabalho se constitui um limite para a organização e mobilização social, mas não é um impeditivo para tal e as assistentes sociais já foram mais organizadas e mobilizadas, mas, ainda assim, consideram que as assistentes sociais continuam bem organizadas e mobilizadas, o que contribui com o processo de construção da PAE. Houve também uma problematização acerca do que caracterizam os processos de organização e mobilização social em seus sentidos ampliados, como dimensão política, conforme relato:

Eu só consigo pensar em mobilização social no conceito amplo da mobilização. Acho que isso não tem, a gente fica no plano micro [...]. Seria, por exemplo, ter um processo de discussão de qual é a perspectiva de educação para o Serviço Social. O processo de trabalho faz com que, às vezes, a gente fique só nas respostas imediatas e, muitas vezes, as respostas imediatas só nos cobram o arsenal técnico-operativo de uma determinada intervenção e não uma concepção política, porque concepção de educação é uma concepção política (ÔMECA).

Diante do exposto, torna-se importante destacar que, ainda que o assistente social tenha uma relativa autonomia que proporcione a impressão da direção social do seu trabalho, as instituições empregadoras determinam suas metas a cumprir (IAMAMOTO, 2004). Contudo, compreendemos que o desenvolvimento da dimensão política do serviço e, portanto, os processos de organização e mobilização social, não podem recuar em frente a essa realidade. 
Sigma considera que a PAE pode ser utilizada como instrumento de formação política, apresentando-se, portanto, como uma possibilidade para o exercício da cidadania:

É um documento que tem que ser construído coletivamente e discutido e tem esse viés político, inclusive frente aos desmontes e à resistência institucional a outras concepções do que é ensino (SICMA).

Salientamos que cidadania, conforme Yazbek (1999) ocorre quando os subalternos se constituem em atores políticos com um projeto de classe. Dessa forma, concordamos que o assistente social pode oferecer contribuições ao fortalecimento da cidadania a partir do desenvolvimento da dimensão política e cultural do exercício profissional, demonstrando que está caminhando juntamente com o usuário das políticas sociais, nas quais atua (YAZBEK, 2014), por meio do incentivo às formas de organização e mobilização social dos estudantes.

\section{Organização e mobilização social dos estudantes}

A organização e a mobilização social estudantil na PAE iniciaram durante a elaboração do documento-base da política, quando suas demandas foram debatidas nos campi e encaminhadas ao Fiae. Além disso, destacamos que alguns discentes são convidados a participar, de forma representada, em encontros eventuais sobre assistência estudantil:

a gente tem um exemplo que foi um fórum [...] de assistência estudantil, em que os estudantes [...] colocaram questões [...] interessantes, a gente debateu e foi tendo um protagonismo muito bom nesse debate honesto e franco sobre as dificuldades (SICMA).

Essa participação dos discentes foi destacada, tendo em vista que eles não são membros efetivos desse fórum e, portanto, não é comum que eles sejam convidados para esses espaços de discussão. Assim, essa experiência se apresenta como uma possibilidade aos processos de organização e mobilização estudantil. 
Sobre a CCPAE, alguns participantes consideram que a PAE não demanda a participação estudantil. Assim, não existe tal representação em todos os campi, o que se constitui um limite. De acordo com relatos, a não abertura para participação se deve ao fato da existência de uma relação de cuidado da equipe referente ao sigilo dos assuntos discutidos: "é muito complicado porque, às vezes, a gente trata questões que o aluno não poderia ouvir" (GAMA).

Assim, acreditamos ser necessária a ampliação do conceito de participação, de forma que ultrapasse os espaços tradicionais de reuniões. É preciso pensar a participação estudantil num viés de que a PAE precisa ser discutida por seus usuários e, portanto, incentivada. Conforme orientação de Beta aos discentes:

tem essa representação na comissão. Vocês têm que estar em contato também com esses representantes, se organizem. Querem mudar alguma coisa? então vocês devem se organizar.

Consideramos a representação de estudantes nos espaços de discussão da assistência estudantil como uma grande possibilidade para a organização e mobilização social, ainda que eles estejam em processo de construção para ocupação desse lugar, conforme relato:

A gente já aprovou que tenha uma participação dos alunos, entretanto eles tiveram dificuldade para eleger esse representante. O grêmio é novo aqui, no campus, e só representa o integrado (ÔMECA).

Compreendemos que é necessário considerarmos que a PAE ainda é uma política jovem, os discentes estão em processo de formação humana e, historicamente, no Brasil, temos um panorama de não participação social:

o programa específico, de alguma forma, é um programa assistencialista, e cria essa relação imediatista. E acho que nós não temos uma formação de participação. É uma formação passiva dentro das políticas sociais (ÔMECA). 
Isso porque, de acordo com Martins (2012, p. 227),

[...] marcados pela cultura de não participação, traço histórico e ideológico imprimido aos brasileiros, os sujeitos envolvidos com a escola pública permanecem no imobilismo, cristalizando preconceitos, fatalismos e omissões. Eles não se veem como sujeitos capazes de intervir nos rumos da educação. Desta forma, raramente discutem a função social da escola e os papéis que cada um exerce no processo educativo.

Identificamos, contudo, a possibilidade de participação estudantil coletiva de maneira concreta em outros campi: "a gente percebe que eles têm esse entendimento sobre as demandas coletivas, para além daquilo que é anseio individual" (SICMA).

No entanto, é importante destacarmos que, mesmo aqueles campi que permitem a participação dos discentes nos espaços consultivos, apresentam limites para o processo de organização e mobilização estudantil, pois a participação não se restringe à autorização dos estudantes para frequentar as reuniões, tornando-se necessário identificar e romper com as relações sociais produzidas e reproduzidas nesse espaço, conforme destacado:

É um espaço que inibe a participação? Porque pode ser que o estudante chegue lá com uma série de questões e fique inibido, porque tem o profissional que fala, o outro que critica. Então tem profissionais com altas formações, a maioria doutores, então, às vezes, não sei se esses estudantes ficam intimidados com alguns debates, ou o debate fica elevado demais em algumas questões, pouco explicado para que todos entendam, até para gente às vezes acontece de alguma coisa não está tão bem explicada (SICMA).

Constatamos, portanto, que as relações sociais presentes no espaço escolar podem influenciar, sobremaneira, a pouca representatividade dos discentes nos espaços consultivos. Essas relações sociais não se limitam a uma categoria profissional e podem estar mais evidentes a 
partir da não autorização dos estudantes como membros na CGPAE ou ainda estar veladas, quando a representação está autorizada no documento, mas não ocorre de fato. Esses processos dificultam o exercício da participação das atividades dos Programas da PAE.

Os Programas Universais são pouco reconhecidos como integrantes da PAE, por serem pouco desenvolvidos, dada a insuficiência de recursos financeiros que deslocam a prioridade para os Programas Específicos, de acordo com o relato: "a gente hoje está um pouco mais restrito a essa especificidade de pagar auxílios, por isso a gente não estimula a produção de outros projetos" (SIGMA).

Além disso, o Ifes, por possuir uma formação conteudista, desenvolve algumas atividades extraclasse, mas que continuam conectadas com o conteúdo escolar: "eles não têm tempo de se engajar em quase nada, porque é diuturnamente estudando" (ALFA). De acordo com ÔMECA: "eles têm atividade de cultura, eles têm palestra, mas na relação com as disciplinas e não com a assistência estudantil".

Diante do exposto, constatamos que fatores, como insuficiência de recursos financeiros, falta de incentivo para os estudantes participarem e característica conteudista na formação do Ifes, se constituem como limites para os processos de organização e mobilização dos discentes nos Programas Universais.

Sobre a participação dos estudantes no processo de acompanhamento dos Programas Específicos, observamos, no relato abaixo, uma interpretação verticalizada, que se apresenta como limite da atuação profissional: "Eles são mais apáticos. Raramente um aluno vem dar sugestões" (ALFA).

É importante, portanto, uma problematização que desnude o motivo de tal apatia, que pode estar presente nas relações sociais existentes entre os estudantes e a equipe de assistência estudantil, materializadas, por exemplo, nas condicionalidades dos Programas Específicos, considerando a existência de um termo assinado pelos estudantes. Um dos compromissos assumidos nesse termo é o 
item II: “[...] comparecer em todas as atividades de acompanhamento do programa, assim como aos atendimentos individuais e reuniões, quando solicitado" (INSTITUTO FEDERAL DE EDUCAÇÃO, CIÊNCIA E TECNOLOGIA DO ESPÍRITO SANTO, 2011b), conforme destaca a assistente social Beta: "eles vão pra cumprir a obrigação. Mas, pensando bem, não é algo atrativo. A única coisa é que eles vão com intuito de saber qual vai ser o valor auxílio".

Constatamos que as condicionalidades incidem, sobremaneira, no processo de participação dos estudantes e se constituem como um limite: "fico nesse duelo: se não for obrigatório, não participam e, se for obrigatório, a gente leva a carga de estar impondo. Sou o fiscal da condicionalidade ou esse momento é de enriquecimento?" (DELTA).

Nesse contexto, Martins (2012, p. 25) afirma que

No tecido social repleto de contradições, o assistente social, nas instituições sociais e no âmbito da relação que estabelece com os usuários, deve promover o rompimento com práticas tradicionais de controle, tutela e subalternização, por meio do alargamento dos canais de participação, por meio da ampla socialização de informações sobre direitos e serviços, numa perspectiva democrática.

As organizações estudantis existentes no espaço escolar se apresentam como possibilidades para a organização e mobilização social na assistência estudantil: "a participação se reflete, às vezes, através do $D A^{3}$ : questionamentos, críticas, incompreensões. Eles produzem documentação para a direção geral e a gente responde" (SICMA).

Além disso, a participação dos discentes ocorre por meio de reivindicações individuais ou organização pontual sobre questões pertinentes à assistência estudantil, segundo os assistentes sociais entrevistados:

através do coordenador e dos demais estudantes que, às vezes vêm trazer essas queixas: 'Olha, como humanizar mais nossos espaços? A sala de vivência está assim, o valor do auxílio está defasado' (SIGMA). 
Outras possibilidades para o processo de organização e mobilização estudantil são vislumbradas a partir da implantação nos campi do Núcleo de Arte e Cultura (NAC):

do ano passado pra cá mudou um pouquinho, porque tem o Núcleo de Arte e Cultura que deu um incentivo para questão da música" (BETA) e dos grêmios estudantis: "alguma coisa começou a mudar com a implantação do grêmio, começou a ser um pouco mais participativo. A organização estudantil tem se mostrado mais propositiva (DELTA).

Outras possibilidades abordadas são experiências que perpassam pelo levantamento de opinião dos discentes acerca de temas para discussão: "a gente manda e-mail, fala que vai fazer a reunião, solicita temas que eles tenham interesse, a gente vai tentar buscar algum palestrante. Essa é a parte que a gente julga democrática" (DELTA).

No entanto, compreendemos não ser possível fragmentar a intervenção profissional entre parte democrática e não democrática, considerando a perspectiva gramsciana que uma das condições do exercício democrático

[...] é captar os reais interesses e necessidades das classes subalternas, sentir com elas suas paixões para que se possa efetuar a crítica do senso comum e da herança intelectual acumulada (IAMAMOTO, 2015, p. 77).

Em vista disso, Mioto (2009) afirma que, para o processo educativo alcançar seus objetivos, é fundamental que haja um vínculo entre usuários e profissionais e exista uma relação democrática entre ambos. A partir daí, o usuário, dotado de informação e reflexão, ganha mais autonomia, passando a participar das diversas instâncias da esfera pública, por meio de tomada decisões, ampliando a consciência de sua cidadania.

Esse vínculo pode ser construído a partir da aproximação com os estudantes e se constitui como possibilidade: "porque o Serviço Social só vai se inserir nesse universo acadêmico deles se participar das atividades que a academia proporciona" (ALFA). 
Ademais, as assistentes sociais participantes sugerem possibilidades para o processo de organização e mobilização social dos estudantes:

Fazer uma divulgação da política de assistência estudantil, dizer quais são as possibilidades, além dos auxílios. Eu acho que isso ainda não está bem esclarecido para os alunos (BETA).

Acolher as ideias, atuando junto à organização, auxiliando na identificação da estrutura institucional, para direcionar melhor os estudantes, para que as coisas comecem a acontecer (SICMA).

Deixar emergir novas propostas de intervenção, que fazem parte do nosso Projeto Ético-Político, trabalhar a emancipação humana, estar junto do aluno, construir novos projetos educacionais, como os programas universais (ÔMECA).

Tentar através de uma conversa, através desse 'Projeto-Boas Vindas', pegar com eles um questionário para eles responderem (ALFA). Os momentos que a gente tem de estar juntos com os alunos são nas reuniões iniciais e a única forma que eu vejo seria na divulgação desse espaço, que eles podem falar. Quer falar? vamos falar em conjunto (BETA).

Eu sempre discuto orçamento com eles. Eu acho que devemos aumentar essas discussões, não nos furtarmos a elas (SICMA).

Em vista disso, endossamos a tese de que o assistente social

[...] pode impulsionar formas democráticas na gestão de política e programas, socializar informações, alargar os canais que dão voz e poder decisório à sociedade civil (IAMAMOTO, 2015, p. 78).

Por fim, diante dos dados mencionados, ainda que existam experiências do Serviço Social no sentido de contribuir com os processos de organização e mobilização estudantis, constatamos dois limites principais que incidem sobremaneira nesses processos. Um deles é a postura dividida das assistentes sociais acerca da representação dos discentes na CGPAE. Outro limite principal está presente nas condicionalidades que prejudicam a construção de uma participação que seja dotada de significado para os estudantes. 
Obviamente, não podemos perder de vista que a abertura dos espaços de participação estudantil ou a ressignifıcação das condicionalidades não dependem da vontade do assistente social ou da formalização documental, pois precisam ser construídas de forma coletiva por todos os atores da escola, de modo que sejam rompidas as relações sociais ali presentes.

\section{Considerações finais}

Constatamos que os assistentes sociais acreditam que a dimensão política do Serviço Social é transversal a toda ação profissional e contribui para a autonomia dos estudantes. Ademais, consideram que a utilização da PAE, como instrumento de formação política, subsidia o conhecimento crítico da realidade.

Em vista dos dados da pesquisa empírica, concluímos que, por meio da dimensão política do Serviço Social, os assistentes sociais do Ifes contribuem com a construção emancipatória dos estudantes, a partir do desenvolvimento da direção social e de processos de organização e de mobilização social.

No entanto, verificamos que a dimensão política do Serviço Social do Ifes está mais centrada na direção social do que nos processos de organização e mobilização social, devido: ao entendimento, por parte das assistentes sociais, de que a formação política dos estudantes está pautada na consciência política e, portanto, na direção social do Serviço Social, o que não é suficiente para o processo de emancipação, pois a formação política também diz respeito aos processos de organização e mobilização social; aos limites principais que incidem diretamente nos processos de organização e mobilização estudantil, como as condicionalidades para a participação nos Programas Específicos e a dificuldade de abertura de representação estudantil na CCPAE.

Ademais, esta pesquisa proporcionou compreender que a PAE ultrapassa os limites postos pelo pagamento de auxílio financeiro e se amplia para a construção de possibilidades para o enfrentamento das expressões da questão social que incidem, sobremaneira, na vida dos estudantes. 
Consoante esse processo, constatamos a necessidade de fortalecer a PAE para que o estudante, além de ter condições econômicas para concluir sua formação, seja estimulado a construir uma consciência política que propicie sua organização e mobilização nos movimentos sociais, que ultrapasse os muros da escola e o acompanhe em outros espaços coletivos, inclusive em sua comunidade.

\section{Referências}

ABREU, Marina Maciel; CARDOSO, Franci Gomes. Mobilização social e práticas educativas. In: ABEPSS; CFESS (Org.). Serviço Social: direitos sociais e competências profissionais. Brasília: CFESS/ ABEPSS, UnB, 2009. p. 593-608.

BRASIL. Decreto $n^{\circ}$ 7.234, de 26 de julho de 2010. Dispõe sobre o Programa Nacional de Assistência Estudantil (PNAES). Disponível em: <http:// www.planalto.gov.br/ccivil_03/_Ato2007-2010/2010/Decreto/D7239. htm>. Acesso em: 12 abr. 2015.

BRASIL. Lei $n^{\circ}$ 13.935, de 11 de dezembro de 2019. Dispõe sobre a prestação de serviços de psicologia e de serviço social nas redes públicas de educação básica. Disponivel em: <http://www.in.gov.br/web/dou/-/lei-n-13.935-de-11-de-dezembro-de-2019-232942408>. Acesso em: 5 fev. 2019.

CONSELHO FEDERAL DE SERVIÇO SOCIAL (CFESS) (Org.). Subsídios para o debate sobre o Serviço Social na educação. Brasília, 2011. Disponível em: <http://cfess.org.br/arquivos/subsidios-servico-social-na-educacao.pdf>. Acesso em: 26 jul. 2015.

CONSELHO FEDERAL DE SERVIÇO SOCIAL (CFESS) Código de Ética do/a Assistente Social comentado. São Paulo: Cortez, 2012.

IAMAMOTO, Marilda Villela. As dimensões ético-políticas e teórico-metodológicas no Serviço Social contemporâneo: trajetória e desafios. In: SEMINÁRIO LATINO-AMERICANO DE ESCUELAS DE TRABAJO SOCIAL, 18., 2004. San José, Costa Rica. Anais... Disponível em: <http://www. ts.ucr.ac.cr/binarios/congresos/reg/slets/slets-018-001.pdf>. Acesso em: 12 jun. 2016.

IAMAMOTO, Marilda Villela. O Serviço Social na contemporaneidade: trabaIho e formação profissional. 26. ed. São Paulo: Cortez, 2015. 
IAMAMOTO, Marilda Villela; CARVALHO, Raul de. Relações sociais e Serviço Social no Brasil: esboço de uma interpretação histórico-metodológica. 41. ed. São Paulo: Cortez, 2014.

INSTITUTO FEDERAL DE EDUCAÇÃO, CIÊNCIA E TECNOLOGIA DO ESPÍRITO SANTO (IFES). Resolução do Conselho Superior nº 19/2011, de 9 de maio de 2011. Dispõe sobre a política de assistência estudantil do Ifes. Disponível em: <http://www.ifes.edu.br/images/stories/files/estude_aqui/legislacao/politica_de_assistencia_estudantil.pdf>. Acesso em: 11 abr. 2017.

INSTITUTO FEDERAL DE EDUCAÇÃO, CIÊNCIA E TECNOLOGIA DO ESPÍRITO SANTO (IFES). Portaria $n^{\circ} 1602$, de 30 de dezembro de 2011. Dispõe sobre as instruções da política de assistência estudantil do Ifes. Disponível em: <http:// www.ifes.edu.br/documentos-institucionais/9470-assistencia-estudantil>. Acesso em: 11 abr. 2017.

MARTINELLI, Maria Lúcia. O trabalho do assistente social em contextos hospitalares: desafios cotidianos. Revista Serviço Social e Sociedade, São Paulo, n. 107, jul./set. 2011. Disponivel em: <http://www.scielo.br/scielo. php?pid=S0101-66282011000300007\&script=sci_arttext>. Acesso em: 29 ago. 2015.

MARTINS, Eliana Bolorino Canteiro. Educação e Serviço Social: elo para construção da cidadania. São Paulo: Unesp, 2012.

MINAYO, Maria Cecília de Souza. O desafio do conhecimento: pesquisa qualitativa em saúde. 13. ed. São Paulo: Hucitec, 2013.

MIOTO, Regina Célia Tamaso. Orientação e acompanhamento de indivíduos, grupos e famílias. In: ABEPSS; CFESS (Org.). Serviço Social: direitos sociais e competências profissionais. Brasília: CFESS/ ABEPSS, UnB, 2009. p. 497-512

MOTA, Ana Elizabete. Espaços ocupacionais e dimensões políticas da prática do assistente social. Revista Serviço Social e Sociedade, São Paulo, n. 120, p. 694-705, out./dez. 2014. Disponivel em: <http: //dx.doi.org/10.1590/01016628.005>. Acesso em: 5 set. 2016.

PIANA, Maria Cristina. A construção do perfil do assistente social no cenário educacional. São Paulo: Cultura Acadêmica, 2009.

SANTOS, Silvana Mara Morais dos. Prefácio. In: CONSELHO FEDERAL DE SERVIÇO SOCIAL (CFESS) (Org.). Código de ética comentado do/a assistente social. São Paulo: Cortez, 2012. 
SILVA, Marcela Mary José da. O lugar do Serviço Social na educação. In: SILVA, Marcela Mary José da (Org.). Serviço Social na educação: teoria e prática. Campinas: Papel Social, 2012. p. 15-32.

WITIUK, Ilda Lopes. A trajetória sócio-histórica do Serviço Social no espaço da escola. 2004. 327 f. Tese (Doutorado em Serviço Social) - Programa de Pós-Graduação em Serviço Social, Pontifícia Universidade Católica de São Paulo, São Paulo, 2004. Disponível em: <cress-sc.org.br/img/noticias/A-TESE-ILDA\%2Oeducacao.doc>. Acesso em: 5 maio 2016.

YAZBEK, Maria Carmelita. Classes subalternas e assistência social. 3. ed. São Paulo: Cortez, 1999.

YAZBEK, Maria Carmelita. A dimensão política do trabalho do assistente social. Revista Serviço Social e Sociedade, São Paulo, n. 120, p. 677-693, out./ dez. 2014. Disponível em: <http://www.scielo.br/pdf/sssoc/n120/05.pdf>. Acesso em: 8 maio 2017.

\section{Notas}

1 Mestre em Políticas Públicas e Desenvolvimento Local pela Escola Superior de Ciências da Santa Casa de Misericórdia de Vitória (EMESCAM). Assistente Social do Instituto Federal de Educação, Ciência e Tecnologia do Espírito Santo (Ifes). Brasil. ORCID: 0000-0001-9677-3486. E-mail: ericagilbra@gmail.com

2 Doutora em Educação pela Universidade Federal do Espírito Santo (Ufes). Professora adjunta da Escola Superior de Ciências da Santa Casa de Misericórdia de Vitória (EMESCAM). Brasil. ORCID: 0000-0003-1028-4265. E-mail: angelacaulyt@ yahoo.com.br.

3 DA - Diretório Acadêmico. 